\title{
Amelanotic Ciliochoroidal Melanoma in a Patient with Oculocutaneous Albinism
}

\author{
Meera D. Sivalingam ${ }^{a} \quad$ Lauren A. Dalvin $^{a}$ b Carol L. Shields $^{a}$ \\ Arman Mashayekhi ${ }^{a}$ Jerry A. Shields ${ }^{a}$ \\ ${ }^{a}$ Ocular Oncology Service, Wills Eye Hospital, Thomas Jefferson University, Philadelphia, PA, USA; \\ ${ }^{b}$ Department of Ophthalmology, Mayo Clinic, Rochester, MN, USA
}

\section{Established Facts}

- Oculocutaneous albinism is associated with decreased visual acuity, optic nerve hypoplasia, photophobia, and nystagmus.

- Patients with albinism are at increased risk of developing UV radiation-induced skin lesions, including actinic keratosis, squamous cell carcinoma, and basal cell carcinoma; melanoma is rare.

\section{Novel Insights}

- Patients with oculocutaneous albinism can develop uveal melanoma.

- Our case represents the 5th reported case of uveal melanoma in an albino patient.

\section{Keywords}

Albinism · Melanoma - UV radiation - Eye

\begin{abstract}
To report a case of amelanotic ciliochoroidal melanoma in a patient with oculocutaneous albinism. A 76-year-old Caucasian male with a past medical history of oculocutaneous albinism and recurrent urothelial carcinoma was found to have a mass in the left eye, suspicious for ciliochoroidal melanoma. On examination, visual acuity was 20/400 in both eyes (OU). External examination showed iris transillumination defects. Funduscopic examination OU revealed blonde fundus, optic nerve hypoplasia, and foveal hypoplasia, con-
\end{abstract}

firmed on optical coherence tomography. Funduscopic examination of the left eye revealed an inferonasal amelanotic ciliochoroidal mass, measuring $12.0 \mathrm{~mm} \times 13.0 \mathrm{~mm} \times 8.8$ $\mathrm{mm}$. There was visible intrinsic tumor vasculature and overlying subretinal fluid. B-scan ultrasonography demonstrated a hypoechoic, dome-shaped mass. The clinical and imaging features were consistent with amelanotic ciliochoroidal melanoma. The patient was treated with iodine-125 plaque radiotherapy. At the 4-month follow-up, the tumor demonstrated regression from $8.8 \mathrm{~mm}$ to $3.2 \mathrm{~mm}$ in thickness. Despite the apparent lack of uveal pigmentation, patients with oculocutaneous albinism can develop uveal melanoma.

(c) 2018 S. Karger AG, Basel

\section{KARGER}

(c) 2018 S. Karger AG, Basel

E-Mail karger@karger.com

www.karger.com/oop
Carol L. Shields, MD

Ocular Oncology Service, Wills Eye Hospital

Thomas Jefferson University, 840 Walnut Street, Suite 1440

Philadelphia, PA 19107 (USA)

E-Mail carolshields@gmail.com 


\section{Introduction}

Oculocutaneous albinism (OCA) is a rare, autosomal recessive condition characterized by congenital reduction or lack of pigmentation of the hair, skin, and eyes. Ocular findings include blonde fundus, poor visual acuity, optic nerve hypoplasia, and nystagmus [1].

OCA is associated with an increased risk of certain types of UV radiation (UVR)-associated cancers, including cutaneous basal cell carcinoma (BCC) and squamous cell carcinoma (SCC) [2]. Luande et al. [3] studied 350 Tanzanians with OCA and found chronic skin damage by 12 months of age, with $30 \%$ of patients developing skin cancer, resulting in death by the $3 \mathrm{rd}$ or 4 th decade of life in the majority of patients with advanced lesions. Despite increased risk for SCC and BCC in these patients, cutaneous malignant melanoma is rare [2]. Choroidal melanoma in patients with OCA is exceedingly rare, with only a few case reports in the literature to date [4-7]. Herein, we report an amelanotic ciliochoroidal melanoma in a patient with OCA and discuss important clinical features compared to previously reported cases [4-7].

\section{Case Report}

A 76-year-old Caucasian male with a past medical history of urothelial carcinoma, treated with transuretheral resection and chemotherapy for 2 recurrences, had suspicious lesions in the liv- er and left eye (OS) on surveillance magnetic resonance imaging at the 2-year follow-up. Liver biopsy revealed malignant melanoma. The patient was referred for ocular oncology evaluation.

On examination, visual acuity was $20 / 400$ in each eye (OU). External examination revealed fair skin, white eyelashes and eyebrows, nystagmus, and iris transillumination defects. Funduscopic examination OU revealed blonde fundi with optic disc hypoplasia and absent foveal light reflexes. Optical coherence tomography documented foveal hypoplasia OU (Fig. 1). Funduscopic examination OS revealed an amelanotic ciliochoroidal mass inferonasally, measuring $13 \mathrm{~mm}$ in basal diameter and $8.8 \mathrm{~mm}$ in thickness with additional features of visible intrinsic vessels and surrounding subretinal fluid. B-scan ultrasonography demonstrated an acoustically hollow, dome-shaped mass with intrinsic pulsations (Fig. 2). These features were consistent with amelanotic ciliochoroidal melanoma in a patient with OCA. The patient was treated with iodine-125 plaque radiotherapy delivering 7,000 cGy to the tumor apex. At the 4-month follow-up, the tumor showed regression from $8.8 \mathrm{~mm}$ to $3.2 \mathrm{~mm}$ in thickness. After receiving treatment for his primary tumor, the patient declined systemic treatment of his liver metastases.

\section{Discussion}

OCA is a group of inherited autosomal recessive diseases caused by a defect in the melanin biosynthesis pathway with a worldwide prevalence of 1 in 17,000 [1]. The degree of hair and skin pigmentation varies greatly, ranging from complete lack of pigment to accumulation of pigment over time [1]. Ocular findings include congenital
Fig. 1. Facial and ocular features of oculocutaneous albinism. a A 67-year-old Caucasian male with oculocutaneous albinism had pale skin, white eyebrows and eyelashes, blue irides, and prominent red reflex, with blonde fundus, absent foveal reflex, and optic nerve hypoplasia (b). c Optical coherence tomography confirmed fovea hypoplasia. d Slit-lamp examination showed 360 degrees of iris transillumination defects.
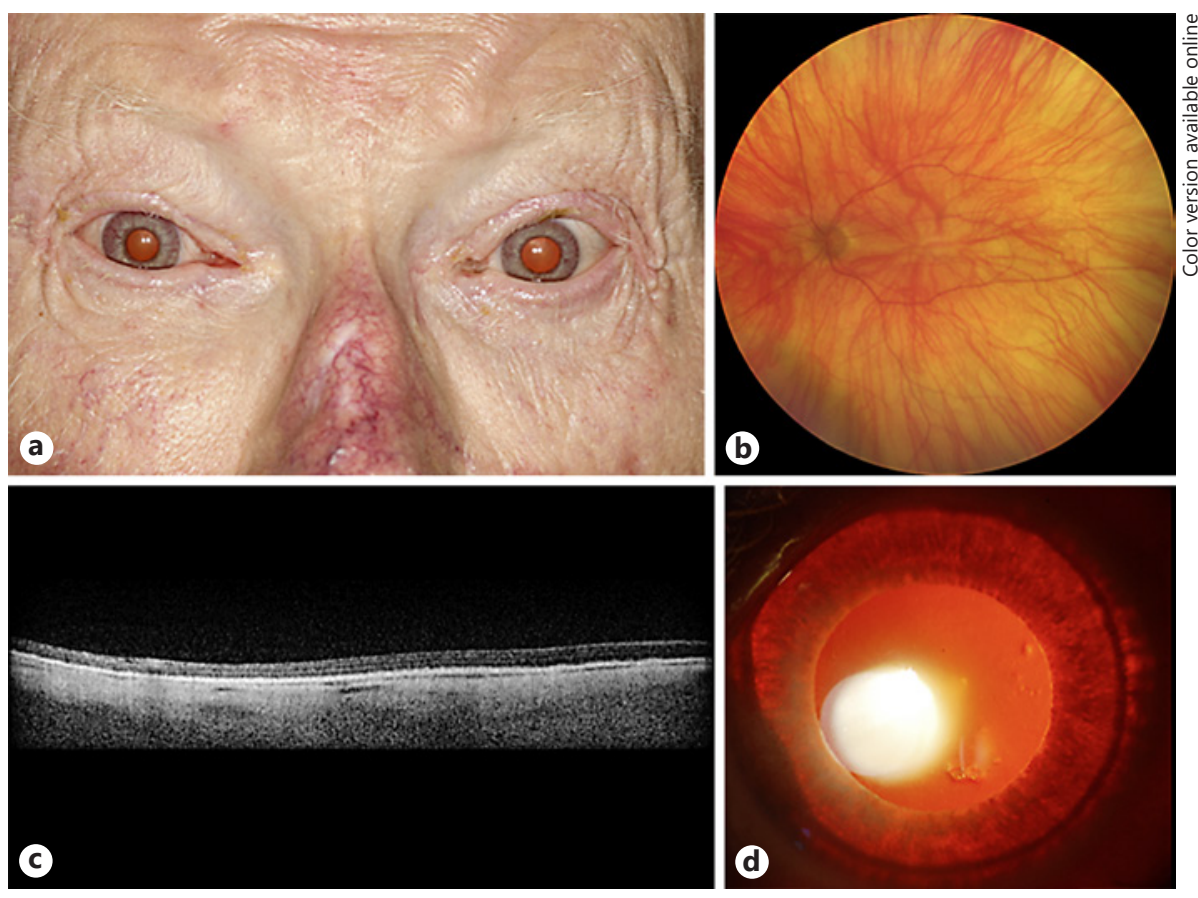
Fig. 2. Amelanotic ciliochoroidal melanoma (a) was noted behind the lens and confirmed on B-scan ultrasonography (b) with acoustically hollow mass measuring 8.8 $\mathrm{mm}$ in thickness.
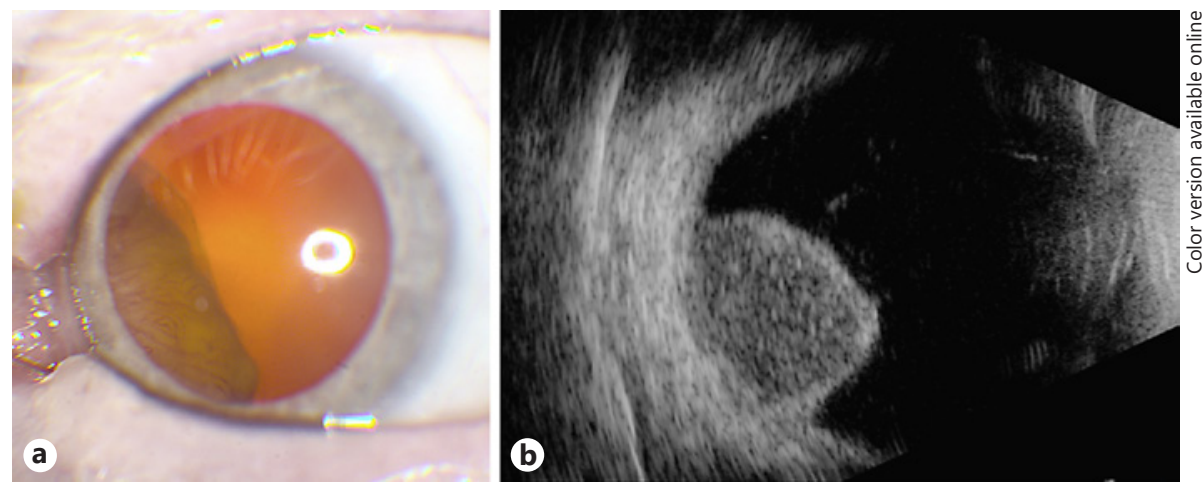

nystagmus, iris hypopigmentation with transillumination defects, foveal hypoplasia, lack of pigment in the retinal pigment epithelium, photophobia, poor color vision, optic nerve hypoplasia, and reduced visual acuity [1].

Melanocytic cancers in patients with OCA are exceedingly rare [2]. Even less common is choroidal melanoma, with only 5 reported cases to date, including the case of ciliochoroidal melanoma reported here [4-7]. Casswell et al. [6] discussed that the theoretical combined incidence of choroidal melanoma in a tyrosinase-positive albino is 1-3 per 100 million, compared to the overall incidence of uveal melanoma in the United States of 5 per million [8]. A summary of clinical features of choroidal melanoma in the 5 reported albino patients include race Caucasian (4/5) or African American (1/5); subtype tyrosinase-positive OCA (1/5), albinoidism (1/5), or undefined (3/5); tumor color amelanotic (5/5), and treatment with iodine-125 radiotherapy (3/5) or enucleation (2/6) [4-7].

While melanocytic tumors are rare in patients with OCA, it is well established that patients are at greater risk of other UVR-induced cutaneous precancerous and cancerous lesions, including actinic keratosis, SCC, and BCC $[2,9]$. UVR is responsible for photocarcinogenesis secondary to structural DNA damage leading to mutations in crucial cell regulatory genes, such as p53 [10]. Cutaneous melanin is a critical protective factor that absorbs and filters UVR to minimize penetration through the dermis [10]. Melanin also absorbs free radicals and functions as a superoxide dismutase [10]. Patients with albinism lack the protective factors of melanin, making them susceptible to chronic solar damage to the skin [11]. Okoro et al. [9] studied 1,000 Nigerian patients with OCA and found by age 20 years, $100 \%$ of patients had malignant or premalignant cutaneous lesions. Lookingbill et al. [12] studied cutaneous cancers in 164 albinos and found $91 \%$ of patients had actinic keratosis and $34 \%$ of patients $\geq 30$ years old had cutaneous malignancy.
While increased UV exposure is a risk factor for cutaneous melanoma, albino patients rarely develop cutaneous melanocytic cancers [13]. Ihn et al. [14] found 23 reported cases of cutaneous melanoma in patients with OCA, a majority of which were amelanotic. The presence of amelanotic melanoma suggests that a melanocyte is required for the formation of melanoma, but the production of melanin is not. However, why cutaneous and ocular melanocytic tumors are seldom found in albinos remains unknown, enforcing the complexity of melanoma pathogenesis. Perhaps inherent molecular differences in albino melanocytes alter proliferative potential. Alternatively, melanoma in albinos could be underrecognized because of the amelanotic appearance.

In our case, the amelanotic appearance of the melanoma added to diagnostic complexity given the patient's history of urothelial malignancy. However, urothelial malignancies rarely lead to uveal metastasis. We advised biopsy of the intraocular mass, but the patient refused. Based on clinical and imaging features of the uveal mass and presence of liver tumor that proved to be melanoma, we deduced that the intraocular mass was likely melanoma.

In summary, we describe a ciliochoroidal melanoma arising in a patient with OCA. Despite the apparent lack of uveal pigmentation, patients with OCA can develop uveal melanoma.

\section{Acknowledgement}

Support provided in part by the Eye Tumor Research Foundation, Philadelphia, PA (C.L.S.), an unrestricted grant from Research to Prevent Blindness, Inc. (L.A.D.), and the Heed Ophthalmic Foundation (L.A.D.). The funders had no role in the design and conduct of the study, in the collection, analysis, and interpretation of the data, and in the preparation, review, or approval of the manuscript. Carol L. Shields, MD has had full access to all the data in the study and takes responsibility for the integrity of the data and the accuracy of the data analysis. 


\section{Statement of Ethics}

The patient consented to publication of this report and clinical photographs.

\section{References}

1 Grønskov K, Ek J, Brondum-Nielsen K. Oculocutaneous albinism. Orphanet J Rare Dis. 2007 Nov;2(1):43.

2 Streutker CJ, McCready D, Jimbow K, From L. Malignant melanoma in a patient with oculocutaneous albinism. J Cutan Med Surg. 2000 Jul;4(3):149-52.

3 Luande J, Henschke CI, Mohammed N. The Tanzanian human albino skin. Natural history. Cancer. 1985 Apr;55(8):1823-8.

4 Shields CL, Frey DM, Pagano W, Shields JA. Choroidal melanoma in a patient with oculocutaneous albinoidism. Retina. 2006;10:10.

5 Kheterpal S, Shields JA, Shields CL, De Potter $\mathrm{P}$, Ehya H, Eng KY. Choroidal melanoma in an African-American albino. Am J Ophthalmol. 1996 Dec;122(6):901-3.

\section{Disclosure Statement}

The authors disclose no conflicts of interest.
6 Casswell AG, McCartney AC, Hungerford JL. Choroidal malignant melanoma in an albino. Br J Ophthalmol. 1989 Oct;73(10):840-5.

7 Harasymowycz P, Boucher MC, Corriveau C, Gauthier D, Allaire G. Choroidal amelanotic melanoma in a patient with oculocutaneous albinism. Can J Ophthalmol. 2005 Dec;40(6): 754-8.

8 Kaliki S, Shields CL. Uveal melanoma: relatively rare but deadly cancer. Eye (Lond). 2017 Feb;31(2):241-57.

9 Okoro AN. Albinism in Nigeria. A clinical and social study. Br J Dermatol. 1975 May; 92(5):485-92.

10 Brenner M, Hearing VJ. The protective role of melanin against UV damage in human skin. Photochem Photobiol. 2008 May-Jun;84(3): $539-49$.
11 Okulicz JF, Shah RS, Schwartz RA, Janniger CK. Oculocutaneous albinism. J Eur Acad Dermatol Venereol. 2003 May;17(3):251-6.

12 Lookingbill DP, Lookingbill GL, Leppard B. Actinic damage and skin cancer in albinos in northern Tanzania: findings in 164 patients enrolled in an outreach skin care program. J Am Acad Dermatol. 1995 Apr;32(4):653-8.

13 Nishigori C, Yasumizu M, Kawaguchi M, Tomoya Takata et al. Malignant skin tumors in patients with oculocutaneous albinism. J Pigment Disord. 2015;2(10).

14 Ihn H, Nakamura K, Abe M, Furue M, Takehara K, Nakagawa H, et al. Amelanotic metastatic melanoma in a patient with oculocutaneous albinism. J Am Acad Dermatol. 1993 May;28(5 Pt 2):895-900. 